\title{
A study on foetal outcome after diagnosis of oligohydramnios at term in tertiary care center
}

\author{
Sunanda K. M.*, Sudha H. C.
}

Department of Obstetrics and Gynecology, Bangalore Medical College and Research Institute, Bengaluru, Karnataka, India

Received: 01 September 2017

Accepted: 11 September 2017

*Correspondence:

Dr. Sunanda K. M.,

E-mail: drsunandaswamy@gmail.com

Copyright: (c) the author(s), publisher and licensee Medip Academy. This is an open-access article distributed under the terms of the Creative Commons Attribution Non-Commercial License, which permits unrestricted non-commercial use, distribution, and reproduction in any medium, provided the original work is properly cited.

\begin{abstract}
Background: Oligohydramnios is associated with a variety of ominous pregnancy outcomes such as foetal distress, low birth weight, perinatal morbidity and increased incidence of Caesarean section. Objective of present study was to determine the outcome of maternal and Foetal wellbeing after diagnosis of oligohydramnios at term pregnancy.

Methods: 50 pregnant women aged between $18-27$ years were screened with history of oligohydramnios by ultrasound scanning after 37 completed weeks, compared with 50 controls with no oligohydramnios.

Results: The mean age of the study group was 22.7 years and of the control group was 22.4 years, respectively. Majority of the patients were primigravidae in both the groups. The mean gestational age was 39.5 weeks in study group and 39.4 in control group. The occurrence of non reactive NST was more in study group compared to the control group. The efficacy of AFI as a screening test to predict foetal distress is more significant with Positive Predictive Value of $57 \%$ and Negative Predictive Value of $80 \%$. The mean birth weight was $2.5 \mathrm{~kg}$ in the study group compared to $2.75 \mathrm{~kg}$ in the control group which is statistically significant. $34 \%$ of the newborns were admitted to NICU in study group compared to $14 \%$ in the control group.

Conclusions: In the presence of oligohydramnios, the occurrence of non-reactive NST, meconium stained liquor, development of foetal distress are very high.
\end{abstract}

Keywords: Amniotic fluid index, NST, Oligohydramnios

\section{INTRODUCTION}

Amniotic Fluid Index of less than $5 \mathrm{~cm}$ defines oligohydramnios as described by Phelan et al. ${ }^{1}$ Oligohydramnios is associated with a variety of ominous pregnancy outcomes such as foetal distress, low birth weight, perinatal morbidity and increased incidence of Caesarean section. ${ }^{2}$ Despite decades of investigations, the regulation of amniotic fluid volume and composition remains incompletely understood. This results in part from the complexities inherent in the amniotic fluid dynamics, an enigmatic interaction of several sites of amniotic fluid secretion and excretion. The source of amniotic fluid are maternal plasma, diffusion of extra cellular fluid through foetal skin, foetal urine and foetal lung secretions. ${ }^{3}$ The purpose of taking group of women with oligohydramnios at term pregnancy are because of etiology, management and outcome is different in late onset oligohydramnios compared to early onset oligohydramnios. ${ }^{4}$

Numerous factors have been evaluated with respect to the effect of amniotic fluid Including inter observer and intra observer variation, transducer pressure, foetal movements, transducer type, number of gestation and foetal presentation. 
Various methods have been described for ante partum and intrapartum foetal surveillance like NST, CST, VAST, BPP, Doppler velocimetry, FHR tracing, foetal stimulation test and foetal scalp $\mathrm{pH}$ estimation. ${ }^{5}$

This study is conducted to find out the value of oligohydramnios detected via Amniotic Fluid Index in determining perinatal outcome at term and Caesarean section rate in pregnancies beyond 37 weeks. The present study was prospective study carried out on 100 patients at Vanivilas Hospital, Bangalore from October, 2015 to October, 2016.

\section{METHODS}

This is a prospective case control study done from October 2015 to October, 2016 at BMCRI, VVH, Bengaluru. It consists of analysis of pregnancy outcome in 50 cases with diagnosis of oligohydramnios by ultrasound after 37 completed weeks of gestation compared with 50 controls with no oligohydramnios and matched for other variables like age, parity, gestational age and any pregnancy complications.

\section{Inclusion criteria}

- 37 completed weeks of gestation.

- Amniotic Fluid Index, $<5 \mathrm{~cm}$.

- Intact membranes.

- Singleton pregnancy with cephalic presentation.

\section{Exclusion criteria}

- Gestational age less than 37 completed weeks

- Premature rupture of membranes.

- Associated foetal anomalies.

- Malpresentations,

- Multiple gestations.

Only those women who remembered their last date of menstrual period correctly with previous regular cycles and the gestational age calculated by clinical examination and ultrasound were corresponding, that is only good and excellent dates with 37 completed weeks were taken.

For all women, USG was done and AFI was calculated by four quadrant technique, NST was done for all patients. ${ }^{6}$ The management protocol was similar in both study group and control group. All were monitored by continuous electronic foetal heart rate monitoring in labour, each case was assessed as follows;

- Spontaneous/ Induced labour

- Mode of delivery

- Indication of Caesarean delivery ${ }^{7}$

- Colour of liquor

- Placental calcification

- Cord round the neck

- $\quad$ APGAR score8 at 1 and 5 min
- Birth weight of new born

- Admission to NICU

- Perinatal morbidity and mortality

\section{RESULTS}

A larger proportion of women in both the groups of study $(66 \%)$ and control (68\%) are booked cases which shows a comparability with respect to the booking status.

Table 1: Distribution according to the ANC booking status.

\begin{tabular}{|c|c|c|c|c|}
\hline \multirow[b]{2}{*}{$\begin{array}{l}\text { ANC booking } \\
\text { status }\end{array}$} & \multicolumn{2}{|c|}{ Study group } & \multicolumn{2}{|c|}{ Control group } \\
\hline & $\begin{array}{l}\text { No. } \\
(n=50)\end{array}$ & $\%$ & $\begin{array}{l}\text { No. } \\
(n=50)\end{array}$ & $\%$ \\
\hline Booked cases & 33 & 66 & 34 & 68 \\
\hline Unbooked cases & 17 & 34 & 16 & 32 \\
\hline
\end{tabular}

Table 2: Distribution with respect to gravidity.

\begin{tabular}{|l|l|l|}
\hline Gravidity & Study group & Control group \\
\hline $1^{\text {st }}$ gravid & 28 & Number $(\mathbf{n = 5 0})$ \\
\hline $2^{\text {nd }}$ gravid & 0 & 27 \\
\hline $3^{\text {rd }}$ gravid & 5 & 19 \\
\hline $4^{\text {th }}$ gravid & 1 & 9 \\
\hline
\end{tabular}

Most women in both the study and control groups were nullipara followed by while next to follow were third gravidae in study group whereas second gravidae in the control group.

Table 3: Distribution of women according to gestational age.

\begin{tabular}{|lll|}
\hline $\begin{array}{l}\text { Gestational } \\
\text { age (in weeks) }\end{array}$ & Study group & Control group \\
\hline $37-40$ & 20 & Number $(\mathbf{n}=\mathbf{5 0})$ \\
\hline$>40$ & 30 & 23 \\
\hline
\end{tabular}

While the mean gestational age for study group is 39 weeks, that for study group is 39.5 weeks which depict almost matched groups.

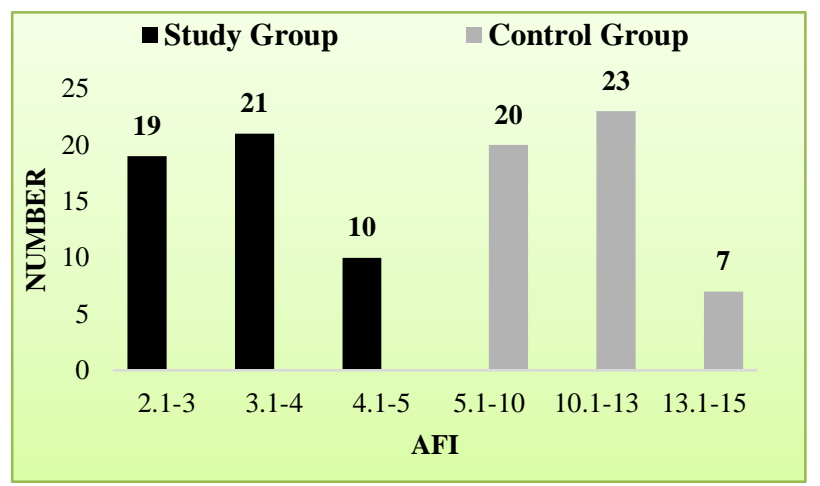

Figure 1: Distribution of AFI in the two groups. 
While the mean AFI in study group was found to be 3.4 $\mathrm{cm}$, the same was $10.82 \mathrm{~cm}$ in the control group.

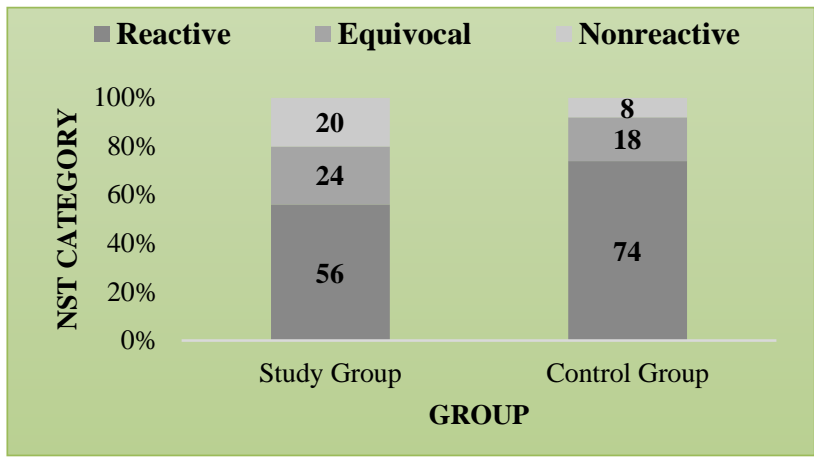

Figure 2: NST Pattern in both groups.

As apparent from Figure 2, the proportion of women with reactive NST was higher among the control group (74\%) compared to those in control group (56\%), whereas those with equivocal and nonreactive NST were higher in the study group $(24 \%, 20 \%$ respectively) compared to the control group (18\%, $8 \%$ respectively).

Table 4: Distribution of colour of the amniotic fluid.

\begin{tabular}{|lllll|}
\hline Colour of & Study group & \multicolumn{2}{c|}{ Control group } \\
amniotic fluid & No. $(\mathbf{n = 5 0})$ & $\mathbf{\%}$ & No. $(\mathbf{n = 5 0})$ & $\mathbf{\%}$ \\
\hline Clear & 24 & 48 & 37 & 74 \\
\hline $\begin{array}{l}\text { Meconium } \\
\text { stained }\end{array}$ & 26 & 52 & 13 & 26 \\
\hline Total & 50 & 100 & 50 & 100 \\
\hline
\end{tabular}

While a proportion of $52 \%$ women in the study group showed the presence of meconium stained liquor, the same in control group was significantly lesser at 265 (p $<0.01)$

Table 5: Distribution according to the type of labour.

\begin{tabular}{|lllll|}
\hline Type of & Study group & \multicolumn{2}{c|}{ Control group } \\
labour & No. $(\mathbf{n = 5 0})$ & $\mathbf{\%}$ & No. $(\mathbf{n = 5 0})$ & $\mathbf{\%}$ \\
\hline Induced & 23 & 46 & 12 & 24 \\
\hline Spontaneous & 27 & 54 & 38 & 76 \\
\hline Total & 50 & 100 & 50 & 100 \\
\hline
\end{tabular}

In the control group, the number of women with induced labour was $12(24 \%)$, while those with spontaneous labour was $38(76 \%)$ whereas the same in the study group was $n=23(46 \%)$ and $n=27(54 \%)$, the difference being statistically significant at $\mathrm{p}<0.03$.

As apparent from Figure 3, while the women delivered by normal vaginal mode predominate in the control group (n $=36$ ), the ones who delivered by Caesarean section mode $(\mathrm{n}=21)$ predominate in the study group. The number women who delivered by the mode of forceps assisted delivery were relatively lesser at 5 and 3 for study and control group, respectively.

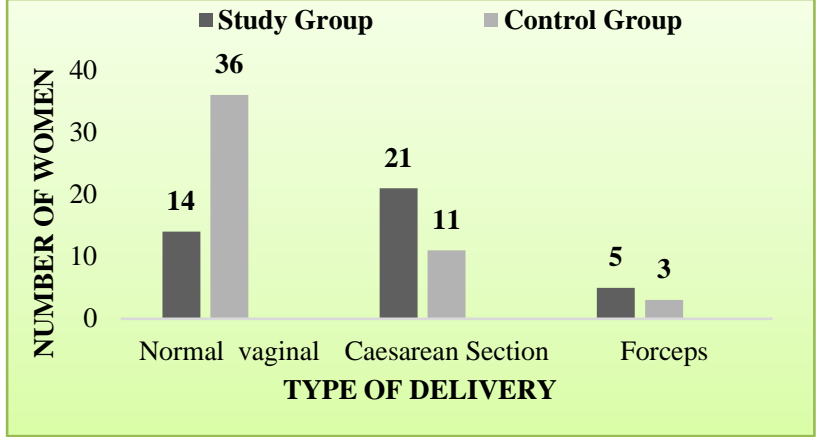

Figure 3: Distribution according to the mode of delivery.

The number of women delivered through LSCS for the reason of foetal distress was higher in the study group (n $=19$ ) while the number in the control group was only 9 . Following the expected trend, the number of normal vaginal deliveries among the women in the control group is 36 while being only 14 in the study group.

Table 5: Distribution according to the parameter of "LSCS for foetal distress".

\begin{tabular}{|lll|}
\hline Parameter & $\begin{array}{l}\text { Study group } \\
\text { No. }(\mathbf{n = 5 0})\end{array}$ & No. $(\mathbf{n}=\mathbf{5 0})$ \\
\hline $\begin{array}{l}\text { LSCS for foetal } \\
\text { distress }\end{array}$ & 19 & 9 \\
\hline $\begin{array}{l}\text { Normal vaginal } \\
\text { delivery }\end{array}$ & 14 & 36 \\
\hline
\end{tabular}

As evident from Figure 4, 23.8\% of babies born by LSCS had APGAR score $<7$ at 5 minutes after birth in the study group, as compared to $18.2 \%$ in the control group which point towards the untoward effect of the oligohydramnios during antenatal period.

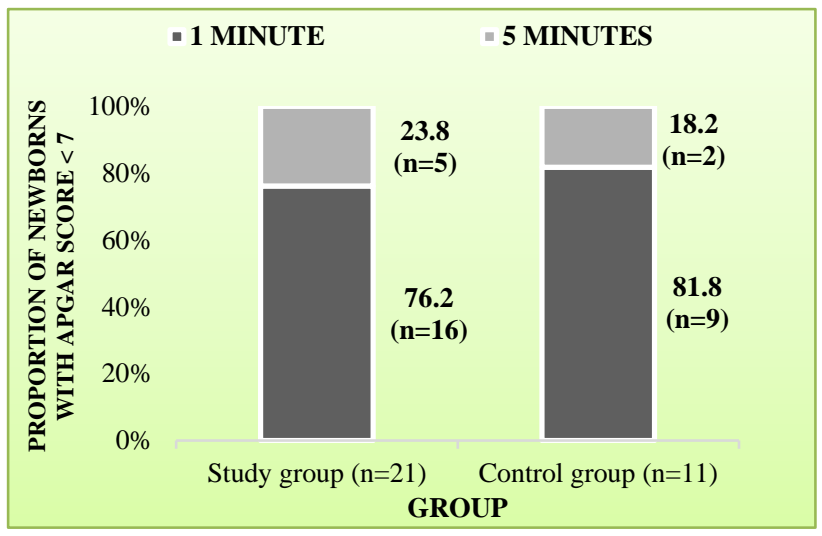

Figure 4: Distribution of neonates born by LSCS according to APGAR score.

The mean birth weight in the study group was $2.58 \mathrm{~kg}$ whereas it was $2.77 \mathrm{~kg}$ in the control group. The proportion of neonates having Low Birth Weight (LBW, i.e., birth weight $<2.5 \mathrm{~kg})$ was around $64 \%(\mathrm{n}=32)$ in the 
study group, whereas it was around $28 \%(\mathrm{n}=14)$ in the control group.

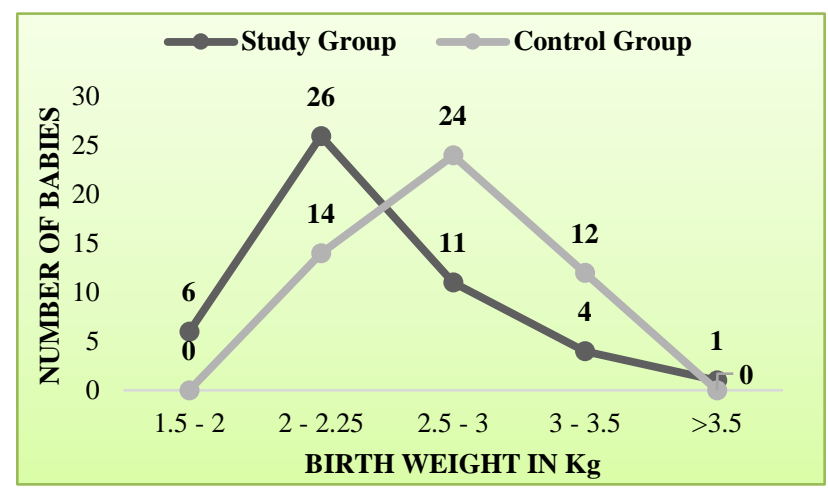

Figure 5: Distribution of neonates according to birth weight.

17 neonates were admitted to NICU in the study group, while the number was only 7 in the control group and this difference was found to be statistically significant ( $\mathrm{p}$ $<0.05)$.

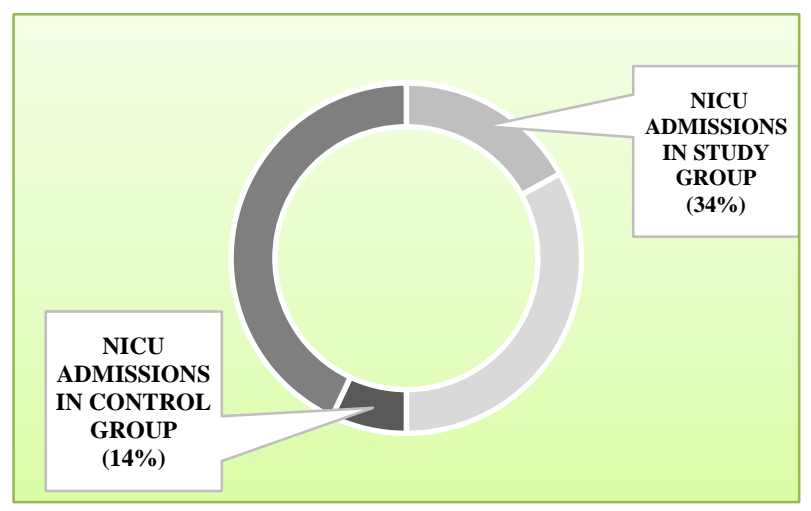

Figure 6: Distribution of children according to admissions to NICU.

\section{DISCUSSION}

This is a prospective case control study carried out at Vanivilas hospital, Bangalore Medical College and Research Centre, Bengaluru from Oct 2016 of 50 pregnant women of more than 37 completed weeks of gestation with oligohydramnios compared with 50 women having AFI more than $5 \mathrm{~cm}$. Other variables like age, parity, gestational age was matched in both groups. The mean age of study group and control group was 22.7 years and 22.4 years, respectively.

Most of them were primigravidae. While the mean gestational age was 39.5 weeks in study group and 39.4 weeks in study group. $32 \%$ of study group had antenatal complications like mild and severe pre-eclampsia, post term pregnancy and abruption placenta.

The Amniotic Fluid Index was measured by four quadrants semi quantitative technique using ultrasound and those with AFI $<5 \mathrm{~cm}$ were considered as oligohydramnios and those with AFI between $5 \mathrm{~cm}$ and $20 \mathrm{~cm}$ were considered normal. ${ }^{1}$ The mean AFI in study group was $3.44 \mathrm{~cm}$ and in control group it was $10.8 \mathrm{~cm}$.

The induction of labour was more common in study group $46 \%$ than in control group $24 \%$. This difference was statistically significant $(\mathrm{p}<0.03)$ which was consistent with several of the previous studies. ${ }^{8,9}$

$44 \%$ of women in study group developed foetal distress, $38 \%$ of them were delivered by LSCS and $6 \%$ by forceps. The difference of intervention for foetal distress between two groups was not statistically significant.

The mean APGAR score at $1 \mathrm{~min}$ and $5 \mathrm{~min}$ were 7.28 and 7.46 respectively in study group whereas in control group it is $10 \%$ and $4 \%$, respectively.

The mean birth weight was $2.5 \mathrm{~kg}$ in study group and $2.75 \mathrm{~kg}$ in control group. The difference in occurrence of low birth weight was statistically significant.

$34 \%$ of neonates in study group was admitted to NICU compared to $14 \%$ of control group, which was statistically significant. These results were consistent with most of the similar studies.

Funding: No funding sources

Conflict of interest: None declared

Ethical approval: The study was approved by the Institutional Ethics Committee

\section{REFERENCES}

1. Phelan JP, Smith CV, Broussard P, Small M. Amniotic fluid volume assessment using the fourquadrant technique in the pregnancy at 36-42 weeks gestation. J Reprod Med. 1987;32(7):540-2.

2. Chamberlain PF, Manning FA, Morrison I, Harmann $\mathrm{CR}$, Lang CR. The relationship of marginal and decreased amniotic fluid volume to perinatal outcome. AMJ Obstet Gynecol. 1984 Oct 1;150(3):245-9.

3. Cunningham F. Williams obstetrics / [edited by] Cunningham FG, Leveno KJ, Bloom SL, Spong CY, Dashe JS, Hoffman BL, Casey BM, Sheffield JS. $24^{\text {th }}$ ed. New York: McGraw-Hill Education/Medical; 2014.

4. Ulkumen B, Pala H, Baytur Y, Koyuncu FOutcomes and management strategies in pregnancies with early onset oligohydramnios. Clin Experiment Obstet Gynecol. 2015;42(3):355-7.

5. American college of obstetricians and gynecologists. Antepartum fetal surveillance. practice bulletin no 9 . Obstet Gynecol. 2014;145:182-192.

6. Rutherford SE, Phelan JP, Smith CV, Jacobs N. The four-quadrant assessment of amniotic fluid volume: an adjunct to antepartum fetal heart rate testing. Obstet Gynecol. 1987 Sep 1;70(3):353-6. 
7. Shrem G, Nagawkar S, Hallak M, Walfisch A. Isolated oligohydramnios at term as an indication for labor induction: a systematic review and metaanalysis. Fetal Diagnos Therapy. 2016;40(3):161173.

8. Watterberg KL, Aucott S, Benitz WE, Cummings JJ, Eichenwald EC, Goldsmith J et al. The apgar score. Pediatrics. 2015 Oct 1;136(4):819-22.

9. Rossi A, Prefumo F. Perinatal outcomes of isolated oligohydramnios at term and post-term pregnancy: a systematic review of literature with meta-analysis. Eur J Obstet Gynecol Reprod Biol. 2013;169(2):149154.

Cite this article as: Sunanda KM, Sudha HC. A study on foetal outcome after diagnosis of oligohydramnios at term in tertiary care center. Int $\mathbf{J}$ Reprod Contracept Obstet Gynecol 2017;6:4329-33. 